\title{
Saúde urbana e higienismo, o exemplo da França
}

\author{
[ Urban health and hygienism, the example of France
}

\section{Virginie Chasles ${ }^{1}$}

Artigo traduzido do francês por Eliane Kuvasney.

\begin{abstract}
RESUMO - A saúde é um bom indicador de qualidade territorial e nos informa sobre a qualidade do ambiente vivido. A saúde na cidade foi compreendida, por um longo tempo, através das topografias médicas, que puderam evidenciar os riscos de saúde ligados à concepção das cidades. Este artigo visa ilustrar as interações antigas entre cidade e saúde. Num primeiro momento, tratar-se-á da apresentação histórica de alguns indicadores de morbidade e de mortalidade, além de alguns fatores de risco. Veremos, em seguida, como a conscientização em relação aos desafios sanitários na cidade pôde influenciar o urbanismo e, através da incorporação do higienismo, como se pôde pensar em preservar a saúde das populações, transformando o seu espaço. Este texto evidenciará o caso da França e da cidade de Lyon. •
\end{abstract} PALAVRAS-CHAVE • Saúde urbana; medicina; higienismo; Lyon. - ABSTRACT · Health is a good indicator of territorial quality and provides information on the quality of the place of life. Health in the city was early apprehended through medical topographies. They were able to highlight the health risks associated with urban building. This article therefore aims to illustrate the interactions between ancient city and health. Firstly, it will be conducted an historic presentation of some indicators of morbidity and mortality, and also of certain risk factors. Then, we will see how the awareness of urban health issues has influenced urban planning. Through the incorporation of hygienism, we will see how we had thought to preserve people health by transforming their place of life. This text will focus on the case of France and city of Lyons. · KEYWORDS - Urban health; medicine; hygienism; Lyons.

Recebido em 21 de março de 2016

Aprovado em 26 de julho de 2016

CHASLES, Virginie. Saúde urbana e higienismo, o exemplo da França. Revista do Instituto de Estudos Brasileiros, Brasil, n. 64, p. 65-74, ago. 2016.

DOI: http://dx.doi.org/Io.II6o6/issn.23I6-90IX.voi64p65-74

I Université Jean Moulin Lyon 3 (Lyon, França). 


\section{INTRODUÇÃo}

A saúde é um indicador reconhecido de desenvolvimento humano e econômico e também de qualidade territorial. Compreender a saúde requer, desse modo, apreender, ao mesmo, tempo as dimensões sociais e espaciais de suas dinâmicas. A esse respeito, a cidade constitui um terreno de observação rico de ensinamentos devido à coexistência, desde sempre, de realidades sociais plurais e de uma diversidade de territórios. De resto, a saúde na cidade foi compreendida há muito tempo, já que as primeiras topografias médicas focaram mais particularmente sobre os espaços urbanos e puderam destacar, em especial, os riscos de saúde ligados à própria concepção das cidades.

Este artigo visa, assim, ilustrar as antigas interações entre cidade e saúde. Inicialmente, tratar-se-á de proceder à apresentação histórica de alguns indicadores de morbidade e de mortalidade, e também de alguns fatores de risco. Veremos, em seguida, como a conscientização com respeito aos desafios ligados à saúde na cidade pôde influenciar o urbanismo e, através da incorporação do higienismo, como se pôde pensar em preservar a saúde das populações transformando seu espaço. Assim, através dos exemplos da França e da cidade de Lyon, examinaremos como a medicalização do espaço foi implementada e como o urbanismo foi influenciado pela medicina, mais particularmente pela revolução pasteuriana (I885) e pela descoberta dos germes.

\section{A CIDADE, UM ESPAÇO PATOGÊNICO DE LONGa DATA}

A cidade há muito tempo se constituiu num espaço de doenças. Durante os últimos séculos, os qualificativos a seu respeito eram também explícitos já que se falava de cidade moribunda, de espaço mortífero preso em seus miasmas ou ainda de berços 
de epidemias assassinas. Essa condição sanitária das cidades antigas foi objeto de numerosos estudos, que eram chamados de topografias médicas. Essas monografias de tipo neo-hipocrático foram numerosas durante os séculos XVIII e XIX na Europa, em especial na França, por iniciativa da Société Royale de Médecine ${ }^{2}$. Essas topografias médicas eram de escalas variadas, indo da região à cidade, como a de Claude Lachaise, sobre Paris 3 . Essa abordagem neo-hipocrática, inspirada no tratado de Hipócrates Ares, águas, lugares, considera que o meio é a origem da maior parte das doenças. Sabine Barles explica que, no século XVIII, a mortalidade e a morbidade são postas sob a perspectiva das características climáticas, meteorológicas e topográficas. É a observação do solo que é então predominante já que está associada a ele a origem principal dos miasmas. Fala-se então de mefitismo para designar o que é malsão, fazendo referência mais particularmente aos vapores terrestres malsãos4.

Empenhando-se em descrever as condições de vida (físicas, demográficas, econômicas...) de populações campesinas ou citadinas e seus estados de saúde, essas topografias médicas permitiram destacar as desigualdades de saúde não só entre as cidades e as áreas rurais, como também entre as próprias cidades, sendo as condições de saúde ainda piores nas cidades grandes, ou até dentro de uma mesma cidade. Esses trabalhos revelavam, dessa forma, diferenciais de saúde entre cidade e campo muito importantes, mais especificamente em termos de mortalidade. Por exemplo, os trabalhos efetuados na região de Marselha pela Société Royale de Médecine no final do século XVIII mostraram que a esperança de vida na cidade era de 22 anos, enquanto no interior da região era de 38 anos 5 . Da mesma forma, em escala nacional, para a década I8I6-I826 as taxas de mortalidade geral atingiam, em média, 36,I\% nas cidades contra $23,7 \%$ no campo ${ }^{6}$. A cidade era, então, considerada como verdadeira moribunda, e os burgueses preferiam, muitas vezes, enviar suas crianças para o campo, onde as condições sanitárias eram melhores7.

Após um período de melhoria, durante a última metade do século XVIII, as condições de saúde declinaram outra vez durante a fase de urbanização rápida ligada à Revolução Industrial. Face às más condições sanitárias das cidades e em resposta às inquietações dos médicos, os poderes públicos de então concordam sobre a necessidade de mudar a cidade. $O$ desenvolvimento do higienismo a partir da metade do século XIX será, portanto, acompanhado da integração progressiva da

2 PICHERAL, Henri. Dictionnaire raisonné de géographie de la santé. Presses Universitaires de Montpellier 3, $200 I$.

3 LACHAISE, Claude. Topographie médicale de Paris. Examen général des causes qui peuvent avoir une influence marquée sur la santé des habitants de cette ville, le caractère de leurs maladies et le choix des précautions hygiéniques qui leur sont applicables, I822.

4 BARLES, Sabine. Les villes transformées par la santé, I8-20ème siècles. Les tribunes de la santé, n. 33, 20 II.

5 RAYMOND, François. Mémoire sur la topographie médicale de Marseille et de son territoire. Mémoires de la Société Royale de Médecine. Anées I777 et I778, Tome 2, p. 66-I40.

6 POUSSOU, Jean-Pierre. La croissance des villes au XIXe siècle. France, Royaume Uni, États-Unis et pays germaniques. Paris: CDU Sedes,I995.

7 LEQUIN, Yves. Mouroirs urbains? Du cycle du choléra à la tuberculose. In: AGUHLON, Maurice (Dir.). Histoire de la France urbaine, tome 4, La ville de l'âge industriel. Paris, Seuil, I983, p. 276. 
saúde nos ordenamentos urbanos. Num primeiro momento isso vai se materializar essencialmente através da melhoria da circulação das águas (canalização das águas servidas) e dos ares (alargamento das ruas), tendo em vista a liberação da cidade de seus miasmas ${ }^{8}$, tornando-a mais salubre. Os grandes trabalhos de saneamento empreendidos em Paris por Haussmann entre I853 e I869 são bastante ilustrativos9. Na mesma época, os médicos vão defender o isolamento ou o afastamento das populações urbanas das atividades nefastas para a saúde (indústrias) ${ }^{\text {Io }}$.

Essas transformações progressivas da cidade, acompanhadas de melhoria das condições de vida, vão dar lugar aos progressos sanitários assinalados. Com efeito, a partir do fim do século XIX, observa-se um nítido retrocesso da mortalidade e um forte aumento da esperança de vida devido ao efeito conjunto dos progressos da medicina e da higiene, bem como da melhoria dos meios e das condições de vida. As taxas de mortalidade geral de Paris e da França, que eram respectivamente $28,4 \%$ o $22,6 \%$ para o período de I853-I860, passam então para $23,8 \%$ e $22,5 \%$ em I882-I89I, depois para I8,4\% e 20,6\% em I900-I90 $4^{\text {II }}$. Quanto à esperança de vida, que era de 36 anos em I820, passa para 46 anos em I900 e 67 anos em I950 ${ }^{\text {I2 }}$.

Do mesmo modo, a mortalidade infantil na França, reveladora da qualidade dos meios e condições de vida, vai diminuir fortemente a partir do final do século XIX, passando assim de $275 \%$ em I800 a I50\% em I900 e 50\% em I950 (está na ordem de $3,5 \%$ atualmente ${ }^{\mathrm{r}}$. Se a mortalidade infantil recuou fortemente, é necessário notar que esses progressos não são unânimes para todas as cidades. Com efeito, se por um lado a situação sanitária é doravante melhor na cidade que no campo, por outro, ela é melhor nas grandes cidades que nas pequenas. Essas disparidades entre cidades vão perdurar. Assim, nos anos I960, a mortalidade infantil é claramente inferior à média nacional em Paris, Lyon e Grenoble. Em contrapartida, as altas taxas persistem em Marselha, Nantes e Rouen e mais ainda nas cidades do Nord-Pas-deCalais e da Lorraine ${ }^{\mathrm{I}}$. Ainda hoje, a distribuição geográfica das taxas de mortalidade infantil é muito desigual: é nas regiões do Nordeste que ela é a mais elevada: $4 \%$ a $5 \%$, enquanto as regiões do Centro e do Sudeste apresentam taxas relativamente baixas: $2 \%$ a $3 \%{ }^{15}$.

Por outro lado, a melhoria das condições de saúde na cidade é acompanhada do

8 CORBIN, Alain. Le miasme et la jonquille: l'odorat et l'imaginaire social aux XVIII et XIXème siècles. Paris: Flammarion, 2008.

9 LÉVY, Albert. Ville, urbanisme et santé, les trois révolutions. Paris: Editions Pascal, 20I2, p. 39.

IO BARLES, Sabine, op. cit.

II POUSSOU, Jean-Pierre, op. cit.

I2 PISON, Gilles. 2004: l'espérance de vie franchit le seuil de 80 ans. Populations et Sociétés, n. 4IO, mars 2005.

I3 Ibidem.

I4 RONCAYOLO, Marcel. Changement dans les pratiques sociales. Histoire de la France urbaine. Paris: Seuil, I985, p. 477.

I5 INSEE - Institut National de la Statistique et dés Études Économiques. Mesurer pour comprendre, 20I3. 
aumento dos desvios entre zonas urbanas e zonas rurais ${ }^{16}$. Desde o início do século $\mathrm{XX}$, numerosos trabalhos mostram que a mortalidade é, na França, mais elevada em meio rural que em meio urbano. Além disso, a mortalidade segue a hierarquia urbana e diminui quando a dimensão das aglomerações aumenta ${ }^{\mathrm{T}}$. Isso se explica em grande parte pela composição social mais favorável nas grandes cidades, o que justifica a menor vulnerabilidade das populações referidas no que diz respeito à morbidade e à mortalidade.

Assim, as condições de saúde tais como foram descritas pelos indicadores estatísticos são agora mais favoráveis na cidade que no campo. Em virtude das evoluções socioeconômicas e urbanísticas, houve uma inversão das lógicas geográficas da mortalidade, e a passagem progressiva de uma sobremortalidade para uma submortalidade urbana.

\section{O HIGIENISMO, UMA REVOLUÇÃO URBANÍSTICA E SANITÁRIA}

A evolução da mortalidade na cidade e do perfil sanitário dos citadinos é resultado de múltiplos fatores, entre os quais se pode citar a melhoria das condições de vida, os avanços da medicina e também a transformação progressiva dos espaços urbanos. No que diz respeito a esse último ponto, desde o século XIX, as grandes revoluções médicas (pasteuriana, freudiana, ambiental) afetaram ao mesmo tempo a saúde e o urbanismo ${ }^{\mathrm{I} 8}$.

A revolução médica que vai impactar mais fortemente os espaços urbanos é a revolução pasteuriana, que dará origem ao higienismo ${ }^{\mathrm{I}}$. Até então, era a concepção miasmática que prevalecia em medicina. Dito de outro modo, até o fim do século $\mathrm{XIX}$, as causas das doenças eram procuradas no ar malsão das cidades (miasmas). Os odores pestilenciais, que circulavam no ar da cidade, eram considerados como um fator de risco para a saúde das populações. A palavra "malária” ("mau ar") é uma das ilustrações: considerava-se que essa doença era causada pelo mau ar (odor nauseabundo) que se desprendia das regiões pantanosas e úmidas.

A esse diagnóstico espacial das doenças, vai ser proposto um remédio também espacial ${ }^{20}$. Em outros termos, decide-se agir sobre esses espaços patogênicos a fim de parar a produção e a difusão dos miasmas mortais. Os engenheiros vão, então, tornar-se os atores principais da cidade e vão começar a realizar grandes trabalhos de saneamento. Entre eles, podemos citar o arquiteto Pierre Patte (I723-I8I4), que vai propor um plano de embelezamento de Paris, preconizando excluir da cidade todas

I6 SALEM, Gérard; RICAN, Stéphane; JOUGLA, Eric. Atlas de la santé en France. Volume: Les causes de décès. Paris: John Libbey Eurotext, 2000.

I7 BOUVIER-COLLE, Marie-Hélène. La mortalité urbaine en France. Courrier du CNRS, n. 8I, I994.

I8 LÉVY, Albert, op. cit., p. 20.

I9 Nota do editor: é importante salientar que tal afirmação não é consenso entre os estudiosos do tema. Alguns autores afirmam que as propostas higienistas para os espaços urbanos são anteriores à revolução pasteuriana. 20 LÉVY, Albert, op. cit., p. 26. 
as atividades poluidoras, alargar as ruas, multiplicar e aumentar as praças, favorecer a circulação do ar e destruir os bairros demasiado densos.

Os médicos vão também estar nessa iniciativa de novas recomendações urbanísticas. Entre eles, pode-se citar Alexandre Parent-Duchatelet ${ }^{2 I}$ (I790-I836), considerado o "pai da higiene pública” na França, que estava convencido do papel protagonizado pelo ar e pela água na saúde das populações urbanas. Empreendeu diferentes ordenamentos e dispositivos, como a construção de esgotos e o tratamento dos resíduos. Sensível às recomendações dos médicos, o prefeito Rambuteau (I78I-I869), que queria “dar aos parisienses a água, o ar e a sombra”, iniciou, ele também, ordenamentos de envergadura: abertura de grandes avenidas, pavimentação de ruas, construção de passeios e de esgotos, plantação de árvores, multiplicação de fontes de água...

Alguns anos mais tarde, é Haussmann (I809-I89I), com seus grandes trabalhos (entre I853 e I869), que vai iniciar uma ação de saneamento radical e em grande escala sobre o conjunto da capital (eliminação da superpopulação e das fortes densidades em certos bairros populares, multiplicação das aberturas de vias, construção de uma rede de água potável, ampliação da rede de esgoto, concepção de parques e de espaços verdes) ${ }^{22}$.

Assim, a partir da metade do século XIX, uma nova cidade vai gradualmente sendo construída a partir dos princípios do espacialismo higienista e do saneamento ${ }^{23}$. Isso se impõe sobretudo porque existe, como visto anteriormente, uma constatação quase unânime no século XVIII, a da sobremortalidade urbana. O termo espacialismo faz referência ao papel medicinal (pharmakon) atribuído ao espaço, que então é mobilizado para fins curativos. O espaço é assim saneado e transformado para poder erradicar as doenças. A forma urbana nova que emerge desses ordenamentos é, por isso, complexa e multiforme. É caracterizada, antes de mais nada, por um urbanismo subterrâneo que esconde as redes de escoamento a fim de conduzir a água aos lares e evacuar para fora da cidade as águas servidas e contaminadas. Aparece, igualmente, um urbanismo neobarroco, com o seu culto do eixo, que traça largas vias retilíneas através da cidade para ligar rapidamente os equipamentos (estações, casernas...) e favorecer também uma melhor ventilação da cidade. Enfim, desenvolve-se um urbanismo paisagístico que distribui na cidade os espaços verdes, os jardins públicos, as praças e milhares de árvores alinhadas para ornamentar essa cidade, e também oxigenar e purificar o ar urbano.

Essa mobilização do espaço com fins terapêuticos vai conhecer novas evoluções a partir do final do século XIX com a revolução pasteuriana, que vai transformar, ao mesmo tempo, a medicina (nascimento da medicina moderna) e o urbanismo (nascimento do urbanismo moderno). Agora são os microrganismos (germes, micróbios, bactérias) que são identificados como únicas e verdadeiras causas das infecções, e que vão ser perseguidos. O urbanismo e a arquitetura vão novamente assumir uma função médica, contribuindo na luta contra os germes causadores de

2 I Ibidem, p. 34.

22 Ibidem, p. 39.

23 Ibidem, p. 27. 
doenças contagiosas, em especial, contra o da tuberculose ("peste branca"), o grande desafio de saúde pública da época ${ }^{24}$.

Considerada como uma doença urbana, vai gerar um medo difuso da cidade e uma rejeição da civilização urbana, opondo a cidade doentia ao campo são. Apesar da descoberta do bacilo da tuberculose por R. Koch (I882), a profissão médica permanece restrita ao nível terapêutico. Vai-se então propor uma medicina espacialista e climática, tendo como método principal a helioterapia. Assim, o novo período que se abre vai impor um novo objetivo: assepsia dos espaços. É necessário matar o germe, desinfetando e esterilizando em meio medicinal, e introduzindo a luz e o sol na cidade e nas habitações.

Esse mito curativo espacial pelo sol, ar e luz terá repercussões consideráveis sobre a evolução das formas urbanas, e dará lugar especialmente à dissolução de certos velhos tecidos urbanos ${ }^{25}$. Os urbanistas modernos vão, assim, condenar o quarteirão central, julgado patogênico. Vão então propor duas alternativas. A primeira concebe uma outra cidade, fora da cidade existente, na periferia ou no campo, em contato com a natureza, capaz de oferecer um ambiente mais são: é o modelo da cidade jardim. A segunda visa melhorar o quarteirão existente, alargando-o, abrindo-o ou destruindo-o, para transformá-lo ou substituí-lo por um tecido urbano aberto a fim de maximizar a entrada de ar, de sol e luz no hábitat: é o modelo da renovação urbana. As consequências desse urbanismo higienista e funcionalista serão fatais para as formas urbanas da cidade antiga (sanitariamente desqualificadas) e para a cidade histórica, que é ameaçada.

\section{LYON, DA INSALUBRIDADE AO HIGIENISMO}

É necessário começar afirmando que, desde sempre, os viajantes que passavam por Lyon salientaram a insalubridade dessa cidade no estreito entre o Rhône e o Saône. É testemunha disso a descrição pouco elogiosa que dava, em I630, numa obra intitulada Voyage de Paris à Rome, um autor chamado Jean-Jacques Bouchard: "A cidade é pouco atrativa, triste e malcheirosa; as ruas muito estreitas, escuras e cheias de lama e as casas altas, escuras, mal construídas..." ${ }^{26}$.

Numerosos são também os autores a dar destaque aos odores tremendos que reinavam na capital dos gauleses devido aos matadouros localizados a céu aberto, no centro da cidade. Durante séculos existiram em Lyon quatro matadouros, respectivamente chamados Terreaux, l'Hôpital, Saint-Georges e Saint-Paul. Esses matadouros, todos localizados no interior da cidade, estavam situados nos bairros mais populosos. Suas ruas estreitas eram malcheirosas, as peles dos animais ficavam penduradas e os açougueiros lançavam nos rios Rhône e Saône seus restos e carcaças de animais. O rio Saône, devido ao curso lento, espalhava, assim, por toda a cidade,

24 Ibidem, p. 54 .

25 Ibidem, p. 63.

26 BOUCHARD, Jean-Jacques apud FRENEY, Jean; DUBOURGET-NARBONNET, Alexandra. Peste, choléra ... et autres calamités. Une histoire des infections à Lyon. Editions EMCE, 20I4, p. 8. 
odores terríveis. Foi necessário esperar o ${ }^{\circ}$ de janeiro de I840 para que o início do funcionamento do abatedouro geral de Perrache suprimisse a presença desses matadouros do meio da cidade ${ }^{27}$.

O mercado dos porcos contribuía igualmente para a insalubridade da cidade. $\hat{E}$ necessário dizer que esse mercado existiu, até ao início do século XVII, no mesmo lugar (no centro da place des Terreaux) onde os condenados à morte, após terem sido pendurados, eram enterrados de maneira sumária pelo carrasco. Quando da montagem desse mercado dos porcos, os cadáveres recentes ou mesmo pútridos frequentemente eram desenterrados e conduzidos pelos animais, o que causava um espetáculo desolador e de odores insustentáveis ${ }^{28}$ !

Assim, até ao início do século XIX, Lyon tinha uma reputação muito ruim, criticada pela intensa insalubridade e por problemáticas preocupantes de saúde, entre as quais a tuberculose ${ }^{29}$, que golpeava sobretudo três bairros populares: a cité Moncey, a Grand-Côte e o bairro Saint-Georges. Esses bairros densos e miseráveis eram verdadeiros lares da doença. As habitações mais atingidas eram as casas dos trabalhadores. A descrição de um alojamento operário, feita por Edme Martin em I9II, permite fazermos uma ideia das condições nas quais viviam certas famílias:

[...] lá só se pode chegar por uma escada escura, tortuosa, estreita e escorregadia cujos degraus usados são úmidos e gordurosos como se suassem a sujeira de uma multidão de gerações. Só uma peça serve de refúgio a toda uma família; se faz tudo neste quarto: se cozinha, se come, se dorme. Uma janela estreita o ilumina num dia sombrio, e, por sua moldura, vê-se sempre o mesmo quadro: está ali, demasiado perto, a alguns metros, o grande muro colado ao pátio ou à rua que se ergue, triste e escura. Um colchão rasgado jogado num canto, uma caixa cheia de trapos ao lado a servir de berço. O pavimento é de uma imundície repulsiva, onde se cospe sem parar e crianças maltrapilhas arrastam-se brincando.

No entanto, a partir da segunda metade do século XIX, numerosos projetos higienistas vão começar a aparecer. Entre os mais importantes, podemos citar o do prefeito Vaïsse ${ }^{30}$ (I799-I864), que esteve na origem de um plano de urbanização que alterou consideravelmente a fisionomia de Lyon, em especial a Presqu'île ${ }^{3 \mp}$. Com efeito, até o Segundo Império a Presqu'île oferecia um emaranhado de ruas que datavam da Idade Média, uma configuração urbana que facilitava a transmissão das doenças infecciosas. Concebido à imagem do plano que o barão Haussmann efetuava paralelamente em Paris, o plano de urbanização do prefeito Vaïsse se caracterizava pela abertura de largas vias, a exemplo da rua Impériale (hoje rua de la République) ou da rua de l'Impératrice (hoje rua Président Edouard Herriot). Claude Marius Vaïsse

\footnotetext{
27 FRENEY, Jean; DUBOURGET-NARBONNET, Alexandra, op. cit., p. Io.

28 Ibidem.

29 Ibidem, p. 40-42.

30 Ibidem, p. 94.

3I A faixa de terras existente entre os rios Rhône e Saône. (N. T.)
} 
esteve igualmente na origem da reformulação do sistema de alimentação de água da cidade (I854), da criação do hospital da Croix-Rousse (I857) e do ordenamento do parque de la Tête-d'Or (I857).

Durante a segunda metade do século XIX, novos ordenamentos ocorrerão (criação de uma distribuição de água de boa qualidade, elaboração da rede de esgotos, sistema de coleta de lixo, instauração da secretaria de higiene em I890) ${ }^{32}$, o que continuará a promover o recuo da insalubridade. É necessário dizer que a cidade de Lyon conta com vários higienistas famosos ${ }^{33}$. Entre eles, podemos citar Antoine Gailleton (I829-I904), médico, que foi prefeito de Lyon de I88I a I900 e estabeleceu numerosas medidas higienistas (criação do serviço de águas, criação da secretaria de higiene...). Há também Gabriel Roux (I853-I9I4), que, em I892, foi nomeado diretor do escritório municipal de higiene de Lyon. Ele assegurou a implementação dos banhos públicos e a distribuição de leite esterilizado aos lactentes necessitados, o que levou à criação de uma estação municipal de esterilização de leite. Gabriel Roux soube detectar os problemas de contaminação das águas ligados à alimentação dos lioneses e lutou contra os problemas da febre tifoide.

Da mesma época, Jules Courmont (I865-I9I7) foi outro higienista importante. Médico e biólogo, foi titular da cadeira de higiene da faculdade de medicina (I900-I9I7). Cofundador e diretor do Instituto Bacteriológico de Lyon, é o primeiro inspetor departamental da higiene pública do departamento do Rhône. Em I907 organiza, em Lyon, uma exposição de higiene urbana. Por fim, Edouard Herriot (I872-I957), prefeito de Lyon de I905 a I957, empreendeu ordenamentos múltiplos: construção de novos abatedouros, de um novo hospital, de uma usina de incineração dos resíduos domésticos (Gerland), de numerosos grupos escolares e alojamentos alugados por baixos valores... e não podemos esquecer que Edouard Herriot desejava derrubar a atual Vieux Lyon. Ele declarou: "a Vieux Lyon é um amontoado de pardieiros, todos dignos de demolição". Edouard Herriot fez parte dos organizadores da Exposição Internacional Urbana de Lyon em I9I4, que visava avançar com o projeto de uma cidade moderna e original, que respondesse às necessidades novas, aos conceitos de higiene e progresso social.

\section{ConClusão}

Em uma escala global, o estado de saúde das populações melhorou enormemente desde o século XIX. É o que expressa o aumento regular da esperança de vida. Ela está relacionada à melhoria das condições de vida (acesso à alimentação e à assistência, progressos médicos, melhoria das condições de trabalho) e também à transformação dos espaços urbanos. Consequentemente, a saúde é um bom indicador da qualidade dos espaços urbanos. Ela também traz consigo elementos de compreensão sobre as evoluções antigas e recentes do urbanismo.

32 Frioux, Stéphane. Les batailles de l'hygiène. Villes et environnement de Pasteur aux Trente Glorieuses. Paris, PUF, 20I3, $388 \mathrm{p}$.

33 FRENEY, Jean \& DUBOURGET-NARBONNET, Alexandra, op. cit., p. 96-Ioo. 
Hoje, essa incorporação da saúde no ordenamento das cidades permanece, como atesta a sua integração aos documentos de urbanismo. Cidade e saúde são, assim, duas dimensões em constante interação. De um lado, a saúde nos informa sobre a qualidade urbana e a paisagem social. De outro, a cidade cresce rica em saúde para oferecer materialidades urbanas favoráveis à saúde das populações.

\section{SOBRE A AUTORA}

VIRGINIE CHASLES é professora do Département de Géographie-aménagement du Territoire, Université Jean Moulin Lyon 3, e integrante da Equipe Hesper (Health Services and Performance Research).

E-mail: chaslesvirginie@yahoo.com

\section{REFERÊNCIAS BIBLIOGRÁFICAS}

BARLES, Sabine. Les villes transformées par la santé, I8-20 ème siècles. Les tribunes de la santé, n. 33, 2011. BOUVIER-COLLE, Marie-Hélène. La mortalité urbaine en France. Courrier du CNRS, n. 8I, I994.

CORBIN, Alain. Le miasme et la jonquille: l'odorat et l'imaginaire social aux XVIII et XIX ${ }^{\text {ème }}$ siècles. Paris: Flammarion, 2008.

FRENEY, Jean; DUBOURGET-NARBONNET, Alexandra. Peste, choléra... et autres calamités. Une histoire des infections à Lyon. Editions EMCE, 20I4.

FRIOUX, Stéphane. Les batailles de l'hygiène. Villes et environnement de Pasteur aux Trente Glorieuses. Paris: PUF, 20I3, $388 \mathrm{p}$.

INSEE - Institut National de la Statistique et dés Études Économiques. Mesurer pour comprendre, 20I3.

LACHAISE, Claude. Topographie médicale de Paris. Examen général des causes qui peuvent avoir une influence marquée sur la santé des habitants de cette ville, le caractère de leurs maladies et le choix des précautions hygiéniques qui leur sont applicables, I822.

LEQUIN, Yves. Mouroirs urbains? Du cycle du choléra à la tuberculose. In: AGUHLON, Maurice (Dir.) Histoire de la France urbaine, tome 4, La ville de l'âge industriel. Paris, Seuil, I983, p. 276.

LÉVY, Albert. Ville, urbanisme et santé, les trois révolutions. Paris: Editions Pascal, 20I2, p. 39.

PICHERAL, Henri. Dictionnaire raisonné de géographie de la santé, Presses Universitaires de Montpellier 3, 2001.

PISON, Gilles. 2004: l'espérance de vie franchit le seuil de 80 ans. Populations et Sociétés, n. 4IO, mars 2005. POUSSOU, Jean-Pierre. La croissance des villes au XIXe siècle. France, Royaume Uni, États-Unis et pays germaniques. Paris: CDU Sedes,I995.

RAYMOND, François. Mémoire sur la topographie médicale de Marseille et de son territoire. Mémoires de la Société Royale de Médecine, Anées I777 et I778, Tome 2, p. 66-I40.

RONCAYOLO, Marcel. Changement dans les pratiques sociales. Histoire de la France urbaine. Paris: Seuil, I985.

SALEM, Gérard; RICAN, Stéphane; JOUGLA, Eric. Atlas de la santé en France. Volume I:Les causes de décès. Paris: John Libbey Eurotext, 2000. 